\title{
POR QUE É RELEVANTE ESTUDAR HOJE A FILOSOFÍA POLÍTICA DE LEO STRAUSS?
}

\author{
José Ricardo Pierpauli \\ CONICET
}

\begin{abstract}
Through a reappraisal of Strauss's political philosophy, this article tries to find a more comprehensive overview of political philosophy in the Middle Ages and its meaning for contemporary political philosophy. If, on the one hand, Strauss chose to follow what is known as medieval rationalism, on the other, the relation between reason and faith characterized the core of his reflection. Strauss was a Jewish author who never forgot his condition, something that defined, from his youth on, the political and theological problem as the major concern of his scientific and academic life. According to such perspective, I will mainly describe the reception of the philosophical and theological model proposed by Maimonides and its integration to the platonic model. Thus, our central thesis is established, namely, that Strauss's project is mainly based on the model created by Moses Maimonides.
\end{abstract}

Keywords: Leo Strauss, political philosophy, Maimonides.

Resumo: 0 objetivo do presente artigo é buscar, através da revalorização da Filosofia Política de Strauss, um panorama mais abrangente da Filosofia Política da Idade Média e seu significado para a Filosofia Política Contemporânea. Se o caminho escolhido por Strauss foi o chamado racionalismo medieval, o eixo de suas reflexões esteve caraterizado pela relação entre Razão e Fé. Strauss foi um autor judeu que jamais esqueceu sua condição, logo, mediante esse eixo orientador, definiu, desde sua juventude, o problema teológico político como a grande preocupação de sua vida científica e acadêmica. Nessa perspectiva, descreverei principalmente a recepção do modelo filosófico e teológico proposto por Maimônides e sua integração no interior do modelo platônico. Deste modo, fica, pois, estabelecida nossa tese central, a saber: 0 projeto straussiano baseia-se principalmente no modelo elaborado por Moisés Maimônides.

Palavras-chave: Leo Strauss, filosofia política, Maimônides. 


\section{0 ponto de partida}

Nosso objetivo é mostrar, no âmbito da comunidade científica brasileira, por que é importante orientar a nossa atenção para a Filosofía Política de Leo Strauss. A tentativa parece justificada pelo fato de ter aparecido até o dia de hoje quase a totalidade da obra do autor em lingua espanhola, italiana, naturalmente em alemão e inglês, mas não em língua portuguesa. Devemos primeiramente salientar as limitações de nossa análise. Com efeito, mostrar a relevância da obra de Strauss não significa necessariamnte explicar a totalidade de suas teses. Significa apenas sugerir linhas de pesquisa a partir do estado atual da questão. Revalorizar o pensamento de Strauss significa, em outras palavras, revalorizar a importância que possui o racionalismo filosófico-político elaborado por Moisés Maimônides, integrado com as teses filosófico-políticas de Platão. Procura-se integrar, através da revalorização da Filosofia Política de Strauss, um panorama mais abrangente da Filosofia Política da Idade Média e seu significado para a Filosofia Política Contemporânea. Se o caminho escolhlido por Strauss foi o chamado racionalismo medieval, o eixo de suas reflexões esteve caraterizado pela relação entre Razão e Fé. Strauss foi um autor judeu que jamais esqueceu sua condição, logo mediante esse eixo orientador, definiu desde sua juventude, o problema teológico político, como a grande preocupação de sua vida científica e acadêmica ${ }^{1}$. Nessa perspectiva descreverei principalmente a recepção do modelo filosófico e teológico proposto por Maimônides e sua integração no interior do modelo platônico. Deste modo fica, pois, estabelecida nossa tese central, a saber: $\mathrm{O}$ projeto straussiano baseia-se principalmente no modelo elaborado por Moisés Maimônides. As eventuais linhas de pesquisa futuras deveriam talvez responder a algumas das seguintes questões: Qual é a verdadeira relação entre Razão e Fé na obra filosófico-política de Strauss? Qual é o tipo de racionalismo que Strauss se propõe reestabelecer no seu retorno a Moisés Maimônides? Qual é o lugar da Filosofia Política nesse contexto? Essa Filosofia Política é útil como ponto de partida para exercer uma crítica do projeto filosófico-político da modernidade?² Tal como Strauss afirma, Maimônides elaborou o modelo do racionalismo nascido no coração da

\footnotetext{
${ }^{1}$ MEIER, H. (ed.). Philosophie und Gesetz Frühe Schriften. In Leo Strauss. Gesammelte Schriften, p. 67. ${ }^{2} \mathrm{~A}$ presente questão estabelece $\mathrm{o}$ horizonte aberto para uma pesquisa posterior.
} 
Idade Media ${ }^{3}$. Esse modelo é mais relevante na medida que é comparado com o racionalismo moderno. Ainda afirma Strauss que somente seria possível conhecer nos seus próprios limites o racionalismo moderno se antes conhecermos nos seus próprios limites o racionalismo medieval inspirado em Maimonides.

\section{Quem foi Leo Strauss?}

A resposta a nossa primeira pergunta abre o caminho para delinear o pensamento de nosso autor. Strauss (1899-1973) foi um autor perseguido no regime nazista e, como tal, vivenciou os perigos que ameaçam a Filosofia em regimes totalitários. Por esse e por outros motivos foi atribuida relevância para a escrita filosófica em tempos de perseguição, como única possibilidade para a sobrevivência do discurso filosófico. A arte de escrever em tempos de perseguição, através da escrita esotérica ou, com outras palavras, da escrita entre linhas ${ }^{4}$, dirigida só para poucos, é, concretamente, a característica que, do ponto de vista metodológico, Strauss observou em Maimônides e Platão.

Strauss estudou Filosofia, Matemática e Ciências Naturais na Universidade de Marburgo, Frankfurt am M., Berlim e Hamburgo. Titulouse doutor no ano de 1921, sob a orientação de Ernst Cassirer. Posteriormente, continuou seus estudos com Edmund Husserl e Martin Heidegger em Freiburf i. Br. Teve de abandonar sua terra, a Alemanha, na época em que era membro da Academia para as Ciências Judaicas. A obtenção de uma bolsa de estudos, oferecida pela organização Rockefeller, permitiu-lhe viajar a Paris em 1932. Mais tarde, recebeu uma nova bolsa da mesma entidade, desta vez para estudar na Inglaterra. Finalmente, no ano de 1938, durante o regime nazista, foi obrigado a emigrar da Alemanha por causa de sua origem judaica. Poderia-se dizer que se encerra nessa data seu primeiro período de produção, dando lugar a outro, talvez o mais conhecido no meio científico, no qual fundou um círculo de seguidores. Essa fase começou no ano de 1938, com sua ida para Estados Unidos, e só acabaria com sua morte, em 1973.

\footnotetext{
${ }^{3}$ Cf. MEIER, H. Op. cit., p. 68.

${ }^{4} \mathrm{Cf}$. Leo Strauss em "The literary character of the Guide for the perplexed". In STRAUSS, L. Persecution and the art of writing, p. 38-94.
} 
Strauss é, possivelmente um dos filósofos políticos mais produtivos do século XX. Suas contribuições vão desde a Filosofia Política de Tucídides até as de Nietzsche e Heidegger. Mas, apesar de aparentemente ser um escritor apenas dedicado à Historia da Filosofia Política, esboçou uma sistemática própria, que está na base das análises que faz dos diferentes autores. Strauss como antes dele Platão, preferiu falar entre linhas escolhendo para tal finalidade a estratégia dos comentadores e não aquela dos tratadistas. Para ele como também para Platão, a Filosofia Política é, por assim dizer, quase uma Filosofia Primeira, pois os homens descobrem seu interesse pelo saber, e pelo saber sobre as coisas mais altas na pólis. Por sua vez, a possibilidade de garantir os direitos da Filosofia na pólis, depende em importante medida da resolução do conflito quase eterno entre sabedoria e poder político. O mito da caverna oferece, ao longo dos escritos de Strauss, uma brilhante imagem do nascimento da Filosofia e da Filosofia Política, em particular. Mas, nessa precária situação - isto é, no fundo da caverna - predominam, como Platão descreve, as opiniões vulgares. Portanto, a tarefa da Filosofia Política é substituir essas opiniões vulgares por conhecimentos científicos certos: "Political philosophy is the attempt to remplace our opinions about political fundamentals bey kowledge about them"5.

Esses conhecimentos rigorosos só poderão ser alcançados a partir de um novo olhar sobre as questões políticas com base na idéia de Deus, pois, para Strauss, a pergunta pelas coisas é na verdade knowledge of $\mathrm{God}^{6}$. Entre Política e Religião há um lugar que dir-se-ia ser o lugar próprio da Filosofia Política. A Filosofia Política é um saber rigorosamente racional, que ganha seus próprios limites entre a Lei Divina e as opiniões políticas nãoilustradas.

Mas como ocorre no mito da caverna, os homens dedicados a elaborar tão alto conhecimento acerca da política deverão enfrentar a incompreensão e até a perseguição por parte do poder político imperante. Com efeito, os problemas que preocupam os homens passam a ser, a rigor, problemas teológico-políticos. Para Strauss, essa foi a situação vivenciada tanto por Platão quanto por Al-Farabi e Maimônides. Estes autores (principalmente Platão) escreveram sobre questões filosóficas a fim de

${ }^{5}$ STRAUSS, L. What is political philosophy?, p. 73.

6 Idem, p. 11. 
alcançar um resultado prático, isto é, mudar a vida na pólis. Portanto, a Filosofía nasceu - para eles - a partir de uma preocupação política, e sua perspectiva última deveria ser teológico-política. Dai a caraterização da Filosofia Política como Filosofia Primeira. Strauss resgata desses autores duas grandes questões. A primeira delas é, como foi dito, de caráter metodológico, e a segunda pertence à ordem sistemática. Com efeito, o filósofo político, inspirado no conhecimento das coisas mais elevadas, deve persuadir através dos seus ensinos, aos demais homens. Mas Strauss observou, no interior da caverna, duas atitudes. Uma a daqueles que consideram a Filosofia como coisa inútil e do passado, que é a atitude que identificou no historicismo do século $\mathrm{XX}^{7}$; a outra, a de intolerância para com a Filosofia por parte do poder político ${ }^{8}$ o que faz do filosofar acerca da verdade uma atitude subversiva.

Desde o ponto de vista sistemático, Strauss decidiu-se pela Filosofia, e pela Filosofia Política em partciular, como modo de vida. Na metade de sua vida, Strauss confrontou, a partir desse esquema geral, os termos ortodoxia e modernidade. Essa controvérsia pode ser observada na temática de suas duas primeiras obras, na Alemanha ${ }^{9}$. No contexto dessa discussão, Strauss alcançou a convicção de que a única possibilidade de defender o discurso filosófico dos ataques do historicismo consiste na sua fundamentação na Religião Revelada, única capaz de oferecer soluções verdadeiramente universais. Daí seu retorno a Maimônides ocorrido em 1938. Maimônides ofereceu ao nosso filósofo as bases apropriadas para a fundamentação da Filosofia Política tipicamente racional, num contexto claramente teológico, por sua vez sustentado na revelação, aceita pela tradição judaica a que Strauss pertence ${ }^{10}$.

A partir da descoberta de Maimônides por Strauss o tema teológicopolítico se converteu, como foi dito, no grande tema de suas reflexões ${ }^{11}$. Ele mesmo reconheceu essa clara orientação no período entre 1965 e 1968. A

\footnotetext{
7 "Whereas, according to the anciens, philosophizing means to leave the cave, according to our contemporaries all pihilosophizing essentiality belongs to a historical world, culture, civilization, Weltanschauung, that is, to what Plato had called the cave. We shall call this view historicism". (STRAUSS, L. Natural right and History, p. 12).

${ }^{8} \mathrm{Cf}$. STRAUSS, L. On Tyranny, p. 22 e sgts.

9 Trata-se das seguintes obras: Die Reilgionskritik Spinozas und zugehörige Schriften (1930) e Philosophie und Gesetz (1935).

10 Cf. MEIER, H. Vorwort des Herausgebers. In STRAUSS, L. Die Religionskritik Spinozas und zugehörige Schriften, p. XII.

11 MEIER, H. Das theologisch-politische Problem. Zum Thema von Leo Strauss, p. 13 e sgts.
} 
esse respeito, pode-se ler o que é considerado o grande eixo da vida e da obra de Strauss, isto é, seu próprio prólogo para a edição americana do texto intitulado Die Religionskritik Spinozas als Grundlage seiner Bibelwissenschaft (1939) ${ }^{12}$. Se até aquele momento a Filosofia Política de Strauss era fundamentalmente platônica, a partir de então Strauss concretizou a inclusão desse platonismo na teologia de Maimônides. Podese dizer que aí nasceu o grande tema de Strauss: a Teologia política. Tomando como base essa nova plataforma, exerceu suas críticas aos modelos filosófico-políticos de Hobbes e de Maquiavel ${ }^{13}$. Resumindo, poder-se-ia dizer que a Filosofia Política de Strauss parte da recepção da Filosofia Política platônica e sua integração no contexto da Metafísica e da Teológica de Maimônides.

\section{A descoberta de Maimónides}

Strauss descobriu a relevância da obra de Maimônides para a Filosofia Política durante seus estudos dos textos de B. Espinosa. O resultado dessa descoberta permitiu a Strauss estabelecer seus próprios pontos de partida na análise da argumentação de Maimônides, pois na sua opinião, este tem mais a dizer para a Filosofia Política e seus atuais problemas do que aquele. Enquanto Espinosa é devedor de uma Filosofia Política sustentada no conceito moderno de natureza, vale dizer, sem relação com a Lei Divina, Maimônides baseia a sua na Lei Divina expressada no Pentateuco, escrita pelo Profeta Moisés. Pode-se comprovar de modo claro o estágio dessa primeira aproximação na argumentação oferecida em Die Religionskritik Spinozas und zugehörige Schriften, Stuttgart-Weimar, 1996. Pode-se comprovar, por sua vez, a escolha de Strauss em favor de Maimônides, na obra intitulada Philosophie und Gesetz, Stuttgart-Weimar, 1997. É exactamente nessa obra que Strauss observou, em Maimônides a possibilidade e os limites do verdadeiro racionalismo ${ }^{14}$. O

\footnotetext{
${ }^{12}$ Cf. STRAUSS, L. Op. cit., p. 6-54.

${ }^{13}$ Cf. MEIER, H. Leo Strauss. In Philosophen Lexikon, p. 862-863.

14 "Nach einem Worte Hermann Cohens ist Maimuni der Klassiker des Rationalismus im Judentum. Dieses Wort scheint uns in einem genauren Sinne richtig zu sein als Cohen es wohl gemeint hat: Maimunis Rationalismus ist das wahrhaft natürliche Vorbild, der vor jeglicher Verfälschung sorgfältig zu hütende Maßstab, damit der Stein des Anstoßes, an dem der moderne Rationalismus zuschanden wird". (MEIER, H. (ed.) Leo Strauss. Philosophie und Gesetz. Beiträge zum Verständnis Maimunis und seiner Vorläufer, p. 9).
} 
núcleo da doutrina de Maimônides que mais impacto teve na obra de Strauss é, segundo as minhas atuais conclusões, do ponto de vista metodológico, a escrita esotérica ${ }^{15}$, e, do ponto de vista temático, a possibilidade de desenvolver um amplo espaço para a racionalidade dentro de um contexto teológico.

Com base na perspectiva histórico-filosófica, pode-se dizer que o pensamento de Strauss é caracterizado principalmente pela recepção da Filosofia Política de Maimônides, que se deu em plena harmonia com a recepção da doutrina política de Platão ${ }^{16}$. Strauss foi primeiramente um pensador platônico. Posteriormente, voltou-se para a obra de Maimônides. A partir das teses políticas do autor judeu, Strauss finalmente descobriu seu interesse pela obra política de $\mathrm{Al}$-farabi ${ }^{17}$, considerado por Maimônides como o segundo grande mestre, depois de Aristóteles $^{18}$. Portanto, a perspectiva de Strauss é possivelmente a mais apropriada para reconstruir um quadro completo das teorias políticas produzidas durante a Idade Média fora dos limites da Revelação Cristã.

\section{Dois argumentos que possibilitaram a integração entre Platão e Maimonides na perspectiva de Leo Strauss: 0 confronto entre Filosofia e Poder e o nascimento da escrita esotérica.}

Para Strauss é ainda verdadeiro que, como ocorre no mito da caverna apresentado por Platão em A República, os sábios - e os profetas, na linha das tradições árabe e judaica - precisam apresentar suas doutrinas só para poucas pessoas. Por isso, Maimônides (e também Platão) ${ }^{19}$ teriam-se

\footnotetext{
${ }^{15} \mathrm{Cf}$. Alfarabius compendium legum Platonis, p. 5; MIMONIDES. The Guide of the Perplexed, p. 18.

${ }^{16} \mathrm{Cf}$. MEIER, H. Leo Strauss. Philosophen Lexikon, p. 860.

${ }_{17}$ Strauss esteve convencido que havia um denominador comum entre as duas Filosofías Políticas: "Il y a, dans la philosophie de Maimonides aussi bien que dans celle de ses maitres musulmans et de ses disciples juifs, une science politique. L'enseignement principal de cette science se resume dans les théses suivantes: les hommes ont besoin, pour vivre, d'une direction et, par conséquent, d'une lo; ils ont besoin, pour vivre bien, pour atteindre la félicite, d'une loi divine qui les dirige non seulment, comme la loi humaine, vers la paix et la perfection morale, mais encore vers l'intelligence des vérités supremes et, par là, vers la perfection supreme, la li divine est donné aux hommes par l'intermédiaire d'un homme qui est prophète, c'est-à-dire qui réunit dans sa personne toutes les qualités essentielles aussi bien du philsophe que celles du législator et du roi; l'activité propre deu próphète c'est la législation". (STRAUSS, L. "Quelques remarques sur la science politique de Maimonid et de Farabi". In MEIER, H. (ed.). Strauss L. Gesammelte Schriften, T. 2, Philosophie und Gesetz, p. 125.

${ }^{18} \mathrm{Cf}$. Carta R. Samuel Ibn Tibbón, In: MAIMÓNIDES. Cartas y testamento de Maimónides, p. 33-34.

${ }_{19}$ Cf. PLATÃO. A República. 331 c, 382 c-d, 415 b-c, 450 d, 494 a.
} 
decidido por um tipo de escrita, chamado esotérica. Eis as razões deste ponto de vista: No fundo da caverna as pessoas permanecem amarradas a suas cadeiras sem poder perceber a realidade tal como ela é. Permanecem amarradas não apenas por causa de uma situação física, mas trata-se, antes de mais nada, de uma limitação para projetar o olhar filosófico sobre a realidade. Nesta cena platônica o poder político, auxiliado pelos sofistas, procura que a situação de ignorância filosófico-política permaneca sem alterações. O poder mesmo sustenta-se na ignorância filosófico-política. Strauss salienta aqui, pela primeira vez, o confronto quase eterno entre Poder e Filosofia.

O verdadeiro filósofo, dito no contexto da recepção dos pontos de vista do racionalismo hebraico de Maimonides, aquele filósofo que aceita a revelação bíblica e, portanto, a possibilidade do milagre (Milagro em espanhol), não apenas é capaz de compreender as aparências na luz do mais alto, mas é capaz de compreender e de explicar todas as coisas na luz de um bem que é identificado com Deus. Portanto, como resultado da integração entre a cena platônica da caverna e a perspectiva sistemática de Maimonides, Strauss propõe a primazia da Lex divina antes que a Filosofia. Dito com outras palavras, a Filosofia deve levar em conta a existência e as exigências da Lex divina muito embora a atividade filosófica seja radicalmente racional.

Mas ocorre que as vezes surgem do confronto entre a justiça dos homens e a justiça de Deus grandes diferenças. Surgem também grandes diferenças quando confrontamos as exigências de uma justiça natural e universalmente aceita e a justiça imposta pelo poder político. A tarefa do autêntico filósofo é primeiramente ensinar a verdade acerca da justiça política, e logo falar de tal modo que o tirano não impeça sua fala filosófica, ou, que a Filosofia Política assegure suas possibilidades na pólis. Para tal fim Strauss acredita legítimo assumir como critério hermenêutico a chamada escrita esotérica, quer dizer, falar ou escrever sem escrever. $\mathrm{O}$ verdadeiro filósofo deve falar para todos e para poucos ao mesmo tempo, deve, como fala Maimonides, esconder as pérolas preciosas da verdade detrás de suas palavras. Desta arte somente as pessoas inteligentes poderiam descobrir sua mensagem, mas ao mesmo tempo essa mensagem filosófica permaneceria oculta para o poder político tirânico. Strauss projetou essas conclusões não apenas para compreender a situação de perseguição dos 
judeus mas também para compreender a situação atual da Filosofia Política diante dos poderes políticos ${ }^{20}$. Esconder as verdades filosóficas por trás de uma fala filosófica explícita quer dizer, exotérica, isso e não outra coisa é escrita esotérica.

Mas esse critério serve também para descobrir aquilo que os grandes autores da Filosofia quiseram nos dizer. Nem todos eles podiam falar abertamente. A doutrina esotérica não se nos apresenta através da aplicação de uma perspectiva puramente subjetiva. Ela é o resultado de deixar aos autores mesmos falar, ler suas obras como uma totalidade e, principalmente, não projetar sobre elas critérios metodológicos alheios aos de seus autores ${ }^{21}$. Dado que trata-se aqui apenas de uma introdução às grandes linhas do pensamento de Strauss, deverá servir como orientação apenas um exemplo. Quando um autor nos apresenta flagrantes contradições numa passagem de seu texto, devemos pesquisar os motivos dessas contradições. Por que o autor diz X quando antes e ao respeito da mesma questão tinha dito Y? Devemos logo reconstruir o significado de ambas afirmações para determinar se alguma delas permanece sem antecedentes na obra do autor. Sem uma dessas afirmações se apresenta como inteiramente injustificada, talvez os motivos sejam devidos a que o autor queria dizer exatamente o contrário. Por acaso, se Y não aparece claramente justificada nos escritos do autor, então Y poderia significar efetivamente $\mathrm{X}$. A mensagem $\mathrm{X}$ está destinada para as pessoas verdadeiramente inteligentes, mas permanece oculto por trás da afirmação $\mathrm{Y}$ que de fato poderia ser imposta coativamente pelo poder político dominante ${ }^{22}$.

\section{Por que é relevante estudar o projeto filosófico-político de um autor judeu que pertence a Idade Média?}

Até hoje, os estudos estiveram orientados para a reconstrução dos modelos filosófico-políticos elaborados no contexto da tradição cristã, durante a primeira metade do século XIII. Nesse contexto, foi salientada em

\footnotetext{
20 "In a considerable number of countries which, for about a hundred years, have enjoyed a practically complete freedom of public discussion, that freedom is now suppressed and replaced by a compulsion to coordinate speech with such views as the government believes to be expedient, or holds in all seriousness. It may be worth our while to consider briefly the effect of that compulsion, or persecution, on thoughts as well as actions". (STRAUSS, L. Perscution and the art of writing, p. 22).

21 "Seine Hermeneutik beanspruchte, die Philosophen der Vergangenheit so zu verstehen, wie sie sich selbst verstanden haben". (TAMER, G. Islamische Philosophie und die Krise der Moderne. Das Verh"ltnis von Leo Strauss zu Alfarabi, Avicenna und Averroes, p. 1).

${ }^{22} \mathrm{Cf}$. STRAUSS, L. Persecution and the art of writing, p. 70-71.
} 
numerosas publicações a importância da pouco conhecida Filosofia Política de Alberto Magno, para pôr em relevo a transferência da quase totalidade das tradições antigas ao mundo cristão, e em especial à obra de Tomás de Aquino. Depois uma detalhada análise das fontes de Alberto e ao final dessa primeira pesquisa, a dinâmica própria das conclusões alcançadas levou-me progressivamente a voltar cada vez mais minha atenção para os modelos de argumentação política oferecidos pelos autores árabes e judeus, especialmente Al-farabi e Maimônides, pois eles ofereceram uma valiosa contribuição que, em confronto com as numerosas contribuições produzidas no âmbito das teorias políticas medievais de origem cristã, parece ainda pouco explorada em nosso meio acadêmico.

As teorias políticas da Idade Média poderiam ser caracterizadas, em seu conjunto, como o intento de harmonizar na medida do possível as exigências dos textos políticos elaborados pelos autores antigos com as novas exigências políticas emergentes desse complexo teológico que conhecemos sob o nome de religiões reveladas. Com efeito, o Isalamismo, o Judaísmo e o Cristianismo ofereceram perspectivas em parte divergentes e em parte coincidentes ${ }^{23}$. Mas em todo caso trata-se de reinterpretar, como Strauss propõe e ao contrário do modelo proposto na modernidade, os problemas filosófico-políticos em termos teológico-políticos, revalorizando ao mesmo tempo a racionalidade. Esta é, concretamente a grande contribuição oferecida por Leo Strauss tanto, para a Alemanha quanto para os Estados Unidos, até a década de $70^{24}$.

O esquema a seguir ilustra graficamente a dinâmica do processo de recepção e transformação das Filosofias Politicas de Platão e Aristóteles, integrando o ponto de vista árabe e judaico:

\footnotetext{
23 "There is no doubt that there are things that are common all three of us, I mean the Jews, the Christians, and the Muslims: namely, the assertion of the temporal creation of the world, the validity of which entails the validity of miracles and other things". (MAIMONIDES. Guide of perplexed, I-71. In LERNER-MAHDI. Medieval Political Philosophy, p. 194).

${ }^{24}$ Cf. SÖLLNER, A. Leo Strauss'Denkweg gegenüber der Moderne. In Jahrbuch Politisches Denken, $p$. 114-118.

${ }^{25}$ Cf. PIERPAULI, J. R. "Alberto Magno y Tomás de Aquino. Sus aportes a la Filosofía Política y Jurídica Contemporánea". In Rivista Internazionale di Filosofia del Diritto, 1, p. 88 -112.
} 


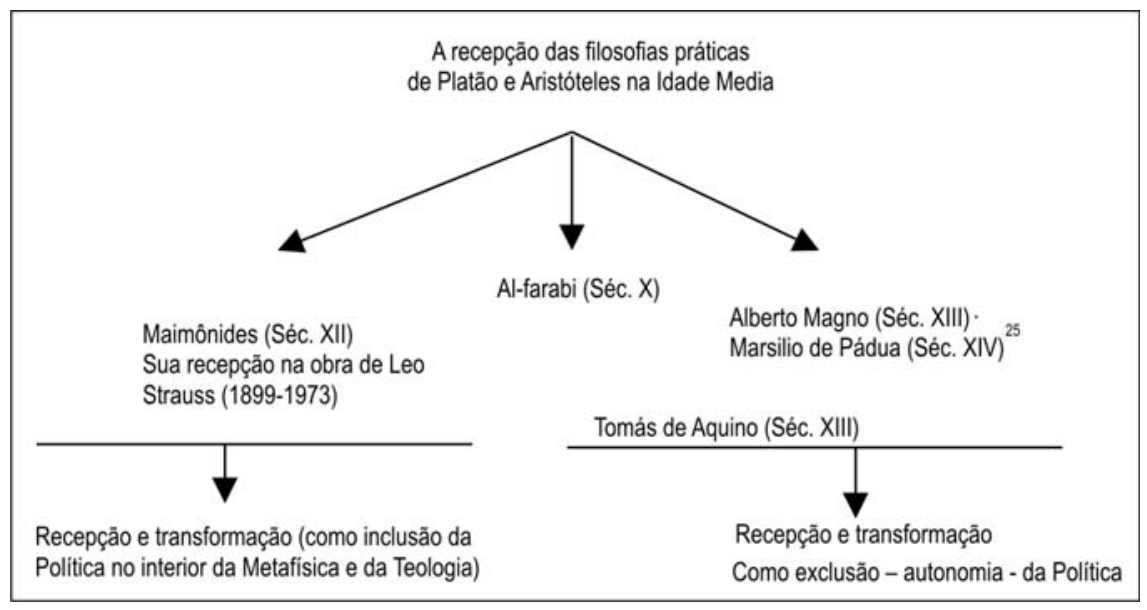

A Filosofia Política elaborada por Alberto Magno, e, posteriormente, por seu discípulo Tomás de Aquino, marcaram, na minha opinião, o fim de um tipo de argumentação filosófico-política integrada claramente a um modelo onto-teológico de raiz neoplatônica, em cujo interior as teses políticas de Aristóteles experimentaram primeiramente um processo de recepção e, em seguida, de transformação ${ }^{26}$. Mas as elaborações posteriores, ou seja, aquelas produzidas pelos discípulos de Tomás, dentro de um contexto parcialmente diferente e caracterizado, de modo especial, pelas disputas entre os poderes religioso e político, por uma parte, e por outro, pelo abandono progressivo da tese da Analogia do Ser, permitiram o nascimento de uma Filosofia Política cada vez mais autônoma em relação à sua fundamentação metafísica e teológica anterior. Fora do círculo dos discípulos de Tomás, o momento mais relevante desse tipo de argumentação foi oferecido por Marsílio de Pádua e, naturalmente por G. de Ockham.

Assim, pois, deve-se entender por recepção o processo de leitura e comentário dos textos políticos de Aristóteles à luz da teologia de base

\footnotetext{
${ }^{26}$ Para uma excelente descrição desse contexto teórico cf. Der Einfluss des Heilige Augustinus auf die Vewertung und Bewertung der Antike im Mittelalter. In GRABMANN, M. Mittelalterliches Geistesleben, T. II, p. 1-24.
} 
neoplatônica. Já Transformação alude, por sua vez, a dois processos, a saber: a inclusão das teses políticas dos antigos, em especial de Aristóteles, no esquema neoplatônico; e o processo de gradual saída da Filosofia Política de seu contexto teológico. Ao final dessa segunda etapa do processo de transformação ficou consolidada uma Filosofia Política de caráter radicalmente autônomo. Bem como outros autores ${ }^{27}$ alcancei a convicção, de que a divisa entre a Filosofia Política Medieval e a Moderna deve estar traçada a partir da segunda metade do século XIII. Foi precisamente aí que nasceram as linhas essenciais do chamado Estado Moderno.

Mas essas conclusões não oferecem ainda um quadro integral acerca das teorias políticas medievais e de seus respectivos níveis de fundamentação teológica. Portanto, faz-se necessário examinar os aportes elaborados pelos filósofos políticos árabes e judeus, dos quais tanto Alberto Magno como seu discípulo, Tomás de Aquino, do ponto de vista geral de seus respectivos sistemas, são devedores em grande medida. Além disso, aparece como urgente a necessidade de evidenciar os aportes que uma confrontação como essa poderia oferecer para a resolução de alguns dos problemas da Filosofia Política atual.

Acaba sendo arbitrário o esquecimento das tradições árabe e judaica, pois é suficientemente conhecido que a obra de Maimônides constitui um importante ponto de partida para compreender a de Tomás de Aquino e que aquela só pode ser entendida a partir de suas relações com o pensamento político, nesse caso - de seu grande mestre, Al-Farabi ${ }^{28}$. Resumindo: uma detalhada compreensão do pensamento político da Idade Média Cristã só pode ser alcançada através do estabelecimento de relações mútuas com as tradições árabe e judaica. Para esse fim, a obra e a figura de Leo Strauss como filósofo judeu constituem o indiscutível ponto de partida.

Desde uma perspectiva sistemática poder-se-ia dizer que a rigor trata-se de três tipos de racionalismo. São eles: o proposto por Alberto e por Tomás no âmbito da Teologia Cristã, o de Marsílio de Pádua, de caráter

\footnotetext{
${ }^{27}$ Cf. VON DER HEYDTE, F. Die Geburtsstunde des souveränen Staates. Ein Beitrag zur Geschichte des Volkrechts, der allgemeinen Staatslehre und des politischen Denkens, p. 10; STENBERGER, D. Drei Wurzeln der Politik, p. 58-71.

${ }^{28}$ Al-Farabi foi considerado o Aristóteles do século X. Suas obras políticas são apenas três, mas, para uma primeira orientação nesse pensamento, é imprescindível a leitura de MAHDI, M. Alfarabi and the Foundation of Islamic Political Philosophy. Chicago-London, 2001. Uma idéia clara do que aqui foi dito se encontra na primeira parte de um importante livro, intitulado Orientation: Philosophy, Jurisprudence and Theology, p. 15-62.
} 
radicalmente autônomo de toda Teologia: e, finalmente, o descoberto e reabilitado por Leo Strauss, inspirado na obra de M. Maimônides. Essa nova perspectiva, unida à recepção da Filosofia Política platônica nesse contexto, permitiu revalorizar os aportes dos filósofos políticos medievais perante as exigências da Filosofia Política atual.

\section{0 caso concreto de Moisés Maimônides na perspectiva de Leo}

\section{Strauss.}

Moshe ben Maimon (1135-1204) nasceu em Córdova de Andaluzia e recebeu sua primeira educação de seu próprio pai, mestre de reconhecida sabedoria. Posteriormente, foi iniciado nos estudos de Ciências Naturais e Filosofia nas escolas muçulmanas. Mais tarde, estudou Medicina no chamado velho Cairo ${ }^{29}$. Sua obra, de caráter enciclopédico, oferece valiosas contribuições à Lógica, à Astronomia, à Medicina e à Teologia. Em seu Commentary on the Mishnah, de 1168, e na chamada Mishna Tora (Code) de 1180, Maimônides tenta descrever a grande complexidade da legislação talmúdica, oferecendo a sua argumentação uma valiosa estrutura sistemática. No conhecido Guide of the Perplexed, de 1185 ou 1190, Maimônides tenta harmonizar a Filosofia dos gregos com as exigências da Lei divinamente revelada no Antigo Testamento. O tratado conhecido como Treatise on the Art of Logic foi escrito quando seu autor tinha aproximadamente 60 anos de idade (1195). Nessa obra, Maimônides oferece pela primeira vez o lugar da Política no campo do saber geral.

Mas, como observa Strauss $^{30}$, o fato de ser este tratado o primeiro em que Maimônides fala abertamente de questões relacionadas à Filosofia Política não significa que o autor não houvesse apresentado anteriormente suas teses e conceitos políticos. É justamente no Guia de Perplexos que Maimônides apresenta conteúdos políticos baseados na observação da natureza humana ao modo aristotélico ${ }^{31}$. Para Strauss, Maimônides, além de

\footnotetext{
${ }^{29} \mathrm{Cf}$. GEYER, B. Die patristische und scholastische Philosophie, p. 339-342.

$30 \mathrm{Cf}$. Leo Strauss em "Maimonides'statement on political science". In STRAUSS, L. What is politcal philosophy?, p. 155-157.

31 Cf. MAIMÔNIDES. Guia de perplexos, cap. I-40, I-71, II-32, II-36, II-37, II-38, II-39, II-40, II-45, III-27, III-28, III-34.
} 
sua condição de teólogo, é o típico racionalista nascido no coração da Idade Média $^{32}$.

Embora Maimônides parta da relevância da profecia (pois sem ela não há Lei Divina), a razão humana não pode se limitar a receber essa lei sem oferecer sua própria contribuição. "Das Gesetz ruft auf zum Glauben die wichtigsten Wahrheiten-an Gottes Existenz, Einheit usw.-Glauben ist aber nicht bloßes Bekannten mit den Lippen, sondern Verständnis des Geglaubten". A racionalidade desenvolve sua tarefa a partir da revelação. É por isso que o Profeta, além de ser o que é, precisa ser também filósofo ${ }^{33}$.

Para Strauss, é incontestável a existência de Deus e de Sua Lei. A Filosofia Política, desde a modernidade, esteve ante seus olhos assim como esteve a realidade para os prisioneiros da caverna em A República de Platão. Dessa forma, a possibilidade da Filosofia radica-se do ponto de vista metodológico, na arte da escrita esotérica, a fim de preservar sua própria vida ante um poder político que não aceita o debate filosófico-político, e do ponto de vista sistemático, na substituição do saber político vulgar, ou seja, dos prisioneiros da caverna, pelo saber verdadeiro sobre o que seria uma ordem política melhor. Mas essa possibilidade só será concretizada com a inclusão da Política dentro da Filosofia e a fundamentação da Filosofia na lei divinamente revelada. "Of Philosophy tus understood, political philosophy is a branch. Political philosophy will then be the attempt to replace opinion about the nature of political things by knowledge of the nature of political things" 34 .

Um conhecimento abrangente e explicativo de todo o real só é possível enquanto conhecimento de Deus. "Quest for knowledge of all things means quest for knowledge of God, the world and man-or rather quest for knowledge of the natures of all things: the natures in their totality are the whole" 35 . Dado, pois, que todas as ações morais e políticas são pensadas tendo em vista a mudança ou a preservação de um determinado estado, todas elas estão orientadas para a boa vida. Essa é, concretamente, a finalidade da Filosofia Política. Uma vez que a natureza das coisas remete

\footnotetext{
32 "Das Gesetz ruft zum Glauben an die wichtigsten Wahrheiten (an Gottes Existenz, Einheit usw.) Glauben ist aber nicht bloßes" (MEIER, H. (ed.). Leo Strauss. Philosophie und Gesetz, p. 75).

33 Deve-se salientar que a doutrina da profecia tem um rol relevante tanto na Filosofia Política dos árabes quanto na dos judeus. Cf. "Quelques remarques sur la science politique de Maimonides et de Farabi". In STRAUSS, L. Philosophie und Gesetz, p. 125-165.

${ }^{34}$ Cf. STRAUSS, L. What is political Philosophy?, p. 12.

35 Idem.
} 
sempre a Deus, Maimônides oferece a nosso autor a possibilidade de substituir a idéia de Bem, formulada por Platão no mito da caverna, pela idéia de um Deus transcendente, que fala através da natureza e de seus profetas $^{36}$. Brevemente, e apenas como ponto de partida, pode-se pois, compreender os termos da integração entre o platonismo político de Strauss e sua preferência pela Teologia Política de Maimônides.

\section{Três paradigmas para a Filosofia Política}

Esses tipos de racionalidade permitem, dentro de uma perspectiva de conjunto, propor três paradigmas para a Filosofia Política, todos eles inspirados no esboço que Strauss intitulou as três ondas da modernidade ${ }^{37}$. O primeiro deles, de argumentação filosófico-política, poderia ser caracterizado mediante a equiparação da Filosofia Política com a Teologia. É concretamente o caso de Platão e de Al-Farabi. O segundo é aquele no qual a Filosofia Política permanece no interior de uma perspectiva teológica mais abrangente, sem perder o elo com seu próprio âmbito. A Filosofia Política é, nesse caso, o resultado da captação da experiência política, e não da interpretação unilateral das Escrituras e dos ditados dos Profetas. Os modelos de Alberto Magno e de Tomás de Aquino, por um lado, e por outro, o modelo de argumentação elaborado por Moisés Maimônides, oferecem um exemplo desse segundo paradigma. Finalmente, o terceiro modelo de argumentação é aquele que caracteriza a modernidade, nascido durante a Idade Média tardia, mais especificamente a partir da segunda metade do século XIII. Nesse modelo, a Filosofia Política se nos apresenta como o pano de fundo do discurso teológico. A Teologia é agora realmente condicionada por uma determinada perspectiva política. É o caso de Marsílio de Pádua e, posteriormente, de Maquiavel e Thomas Hobbes.

A estruturação desses três paradigmas parece mais apropriada para oferecer um quadro detalhado da Filosofia Política não apenas da Idade Média mas também da atual. $\mathrm{O}$ panorama que ofereço permite aceitar o modelo que A. De Libera oferece para a Filosofia Medieval na sua

\footnotetext{
${ }^{36}$ Cf. MEIER, H. (ed.). Strauss L., Philosophie und Gesetz, p. 68. Precisamente no marco desta obra pode-se ler a contribuição talvez mais esclarecedora a respeito desse ponto. Cf. "Die philosophische Begründung des Gesetzes. Maimunis Lehre von der Prophetie und ihre Quellen". In MEIER, H. Op. cit., p. 87-123.

${ }^{37}$ Cf. GILDIN, H. (ed.). Ten essays by Leo Strauss. An Itroduction to political Philosophy, p. 81-98.
} 
totalidade ao salientar que constitui um grave erro pensar que a Filosofia da Idade Média se reduzia apenas ao pensamento cristão ${ }^{38}$. Desse modo a figura e a obra filosófico-política de Leo Strauss apresentam-se como a possibilidade concreta de, primeiramente, preencher o vazio deixado até hoje nos estudos da Filosofia Política Medieval quando se procura inserir neles a Filosofia Política Judaica e, posteriormente, integrar esses valiosos aportes ao eixo argumentativo da Filosofia Política de hoje. Nesse preciso contexto proponho a ideia de continuidade entre Idade Media e Modernidade.

Cabe salientar que a posição filosófico-política de Strauss permitiu também oferecer um novo paradigma para o estudo das figuras mais relevantes da Filosofia Política considerada em sua totalidade ${ }^{39}$. A recepção do modelo platônico junto ao racionalismo de Maimônides constitui o ponto de partida das cuidadosas leituras que Strauss faz das teses desses filósofos. $\mathrm{Na}$ perspectiva que compartilho com Strauss ${ }^{40}$, a Filosofia Política não é apenas objeto de consideração histórica; trata-se de teses em aberto, que deverão ser examinadas à luz de seus próprios contextos, a fim de substituir as opiniões vulgares por conhecimento científico rigoroso e extrair a partir daí novos aportes, que permitirão, possivelmente, resolver os problemas atuais daquela disciplina ${ }^{41}$.

Philosophizing means to ascend from the cave to the light of the sun, that is, to the truth. The cave is the world of opinion as so opposed to knowledge. Men cannot live, that is, they cannot live together, if opinions are not stabilized by social fiat. Opinion thus becomes authoritative opinion or public dogma or Weltanschuung. Philosophizing means, then, to ascend from public dogma to essentialy private knowledge ${ }^{42}$.

\footnotetext{
${ }^{38}$ Cf. DE LIBERA, A. A Filosofia Medieval, p. 7-10.

${ }^{39}$ Com efeito, o modelo proposto por Strauss é radicalmente diferente ao modelo proposto por Georg $\mathrm{H}$. Sabine em A History of Political Theory. (Cf. TARCOV-PANGLE. "Leo Strauss y la Historia de la Filosofía Política". In STRAUSS-CROPSEY. Historia de la Filosofía Política, p. 857-858.

${ }^{40}$ STRAUSS, L. What is political philosophy? p. 56.

${ }^{41}$ Op. cit., p. 10.

42 STRAUSS L. Natural right and History, p. 12-13. Cfr. Op. cit., p. 73.
} 
Embora Strauss se nos apresente como um historiador das ideias políticas, deve levar-se em consideração a clave hermenêutiva oferecida por Strauss mesmo, a saber: Não há uma pesquissa histórico-filosófica que não seja de fato e ao mesmo tempo, uma pesquisa filosófica ${ }^{43}$. Até hoje, o interesse na Filosofia Política da Idade Média oferece um panorama talvez desequilibrado e, o que é talvez ainda pior, pouco interessante. Por uma parte aqueles autores que se interesaram pela Filosofia desse período parecem ter voltado sua atenção para os filósofos que elaboraram suas filosofias políticas no âmbito restringido da Teologia Cristã. Mas são poucas as contribuições dedicadas aos autores judeus e islâmicos, apesar de ser suficientemente conhecido o fato de que os autores dessas tradições receberam também os modelos filosóficos de Platão e de Aristóteles. Precisamente, só uma consideração apenas desse fato levar-nos-ia a refletir os motivos por que os autores judeus e árabes optaram pelo modelo filosófico político de Platão e não pelo de Aristóteles ${ }^{44}$. Ao mesmo tempo, e apesar dos esforços realizados, o interesse nas teorias políticas da Idade Média parece permanecer, na opinião de Strauss, enclausurado nos limites de um passado sem possibilidade de uma releitura atual ${ }^{45}$. Esse é o resultado das contribuições oferecidas por duas importantes correntes de pensamento filosófico delas que nos ocuparemos no decorrer de nosso estudo: elas são o Historicismo e o Positivismo.

\section{Conclusões}

O estudo da obra filosófico política de Leo Strauss, filósofo judeu contemporâneo, permite lançar um olhar diferente e fazer uma nova leitura da Filosofia Política da Idade Média. Desde um ponto de vista geral, podese afirmar que sua obra abriu uma interessante discussão logo após sua morte, ocorrida em 1973. Essa discussão ainda é levada adiante nos Estados Unidos e na Alemanha, onde atuam boa parte de seus discípulos. Por outro lado, o interesse foi recentemente promovido na Alemanha, até mesmo por ser ela a terra de Strauss, onde, após muito tempo, começou a publicação de

\footnotetext{
${ }^{43}$ Cf. Leo Strauss em "Der Streit der Alten und der Neueren in der Philosophie des Judentums", em MEIER, H. Leo Strauss, Philsophie und Gesetz, p. 29.

${ }^{44}$ Cf. Leo Strauss em "Quelques remarques sur la science politique de Maimonide et de Farabi". In MEIER, H. Leo Strauss, Philosophie und Gesetz, p. 127-128.

45 STRAUSS, L. What is political philosophy?, p. 67.
} 
boa parte de sua obra até então inédita ${ }^{46}$. No intuito de oferecer uma perspectiva geral, pode-se dizer que até agora os esforços em torno da obra de Strauss foram realizados em duas grandes orientações: a revalorização das teses de Strauss no contexto dos confrontos com as obras de outros filósofos contemporâneos ${ }^{47}$ e a sua relação com os autores árabes ${ }^{48}$.

A racionalidade que Strauss defende se nos apressenta orientada por uma natureza que recupera o sentido de Mistério que os Filósofos medievais, e de modo especial Maimônides, descobriram por trás desse conceito. Para Strauss e para Maimônides a natureza é criada por Deus. Na ótica de Strauss, a crise da modernidade começou, precisamente, no momento que esse sentido ocultado pela natureza foi abandonado ${ }^{49}$. O lugar da racionalidade só pode ser garantido quando a natureza é concebida como criação, e, dentro dela, a razão, com seus próprios princípios. Se a ordem política é tão-somente o resultado da aplicação dos ditames divinos, então a importância da racionalidade diminui e a Filosofia Política é reduzida a uma mera tarefa legislativa a partir da Lei Divina. Strauss acredita que uma correta valoração do pensamento político de Maimônides só é possível mediante uma prévia valoração de seu mestre árabe Al-Farabi. Com efeito, Al-Farabi oferece tanto os elementos para uma Filosofia Política em conformidade com o racionalismo proposto por Maimônides quanto o modelo da escrita esotérica, também recebido por Maimônides ${ }^{50}$.

A argumentação straussiana nos permite revalorizar o modelo político de base onto-teológica, elaborado durante a Idade Média, e, ao mesmo tempo, inserir o modelo político medieval no contexto das discussões mais atuais da Filosofia Política, pois, o núcleo essencial das

\footnotetext{
${ }^{46} \mathrm{~A}$ edição esta a cargo do Prof. Dr. H. MEIER. Até hoje apareceram os primeiros três volumes.

47 KAUFFMANN, C. Strauss und Rawls. Das philosophische Dilemma der Politik; MEIER, H. Carl Schmitt, Leo Strauss und Der Begriff des Politischen. Zu einem Dialog unter Abwesender, BEHNEGAR, N. Leo Strauss, May Weber, and the scientific study of politics.

48 TAMER, G. Op. cit.

49 "Wenn Gott die Welt nicht in äußerlichem Sinne geschaffen hat, wenn er sie nicht wirklich geschaffen hat, wenn die Schöpfung also nicht auch in theoretischer Absicht- als schlicht wahr, als die Schöpfungstatsache-behauptet werden kann, dann muß man redlicherweise die Schöpfung leugnen, zum mindesten die Rede von Schöpfung vermieden. Alle Verinnerlichungen der Grundbehauptungen der Tradition haben aber ihren Grund darin, dass von der reflektierten Voraussetzung, von der höheren Ebene der nach-aufkläririschen Synthese aus das Verhältnis Gottes zur Natur nicht mehr verstanden werden kann und daher nicht einmal mehr interessiert'. (MEIER, H. Leo Strauss, Philosophie und gesetz, p. 11).

${ }^{50} \mathrm{Cf}$. Leo Strauss em "Quelques remarques sur la science politique de Maimonide et de Al-farabi", In STRAUSS, L. Philosophie und Gesetz, p. 125 e sgts.
} 
idéias de Strauss a respeito dos autores da Filosofia Política Moderna e Contemporânea é fundamentado pela integração da teologia judaica às tradições políticas recebidas dos antigos. Strauss é, nesses termos, a ponte entre a Filosofia Política da Idade Média e a Filosofia Política Contemporânea, por recuperar o estágio pré-filosófico oferecido pela revelação. É precisamente com base nesta conclusão que hoje pode-se afirmar que Strauss é um autor atual, embora voltado para Platão e para Maimônides. Uma primeira leitura da obra de Strauss permite concluir, por sua vez, que a tradição filosófico-política medieval, considerada de modo inetgral, quer dizer, nas suas expressões cristã, árabe e judaica, tem ainda muito para nos ensinar. Eis os motivos que justificam estudar a obra filosófico-política de Leo Strauss. 


\section{Referências bibliográficas:}

ALFARABIUS. Alfarabius, Compendium Legum Platonis. Edidit et Latine vertit F. Gabrieli. Corpus Platonicum Medii Aevi, Plato Arabus Vol. III. London: Warburg Institute. 1952.

BEHNEGAR, N. Leo Strauss, May Weber, and the scientific study of politics. Chicago-London: University Of Chicago Press, 2003.

DE LIBERA, A. A Filosofia Medieval. Trad. D. D. Machado e N. Campánario. São Paulo: Loyola, 1998.

GEYER B. Die patristische und scholastische Philosophie. Basel-Stuttgart, 1967.

GILDIN H. (ed.). Ten essays by Leo Strauss. An Itroduction to political Philosophy. Detroit, 1989.

GRABMANN, M. Mittelalterliches Geistesleben. München, 1946.

KAUFFMANN, C. Strauss und Rawls. Das philosophische Dilemma der Politik. Berlin, 2000.

LERNER-MAHDI. Medieval Political Philosophy. Spurcebook, Ithaka-New York, 1963.

MAIMÓNIDES. Cartas y testamento de Maimónides. Ed. de Carlos del Valle. Córdoba, 1989.

. The guide of Perplexed. Ed. e trad. de Shlomo Pines. University of Chigaco Press, 1963.

MEIER H. (ed.). Leo Strauss, Gesammelte Schriften. Stuttgart-Weimar, 1997.

. Carl Schmitt, Leo Strauss und Der Begriff des Politischen. Zu einem

Dialog unter Abwesender. Stuttgart-Weimar, 1988.

. Das theologisch-politische Problem. Zum Thema von Leo Strauss.

Stuttgart-Weimar, 2003.

. "Leo Strauss". In Philosophen Lexikon. Stuttgart-Weimar, 1992.

PIERPAULI, J. R. “Alberto Magno y Tomás de Aquino. Sus aportes a la Filosofía Política y Jurídica Contemporánea”. Rivista Internazionale di Filosofia del Diritto, 1. Milan: Italia, 2000, p. $88-112$.

SÖLLNER, A. “Leo Strauss'Denkweg gegenüber der Moderne”. In: Jahrbuch Politisches Denken. Stuttgart-Weimar, 1994.

STENBERGER D. Drei Wurzeln der Politik. Frankfurt am Main, 1978.

STRAUSS, L. Natural right and History. Chicago-London, 1965. . Perscution and the art of writing. Chicago-London, 1988. . What is political philosophy? Chicago-London, 1992. 
. Die Religionskritik Spinozas und zugehörige Schriften. StuttgartWeimar, 1996.

. On Tyranny, Chicago-London, 2000,

STRAUSS-CROPSEY. Historia de la Filosofía Política. México, 2000.

TAMER, G. Islamische Philosophie und die Krise der Moderne. Das Verh"Itnis von

Leo Strauss zu Alfarabi, Avicenna und Averroes. Leiden-Boston-Köln, 2001

TARCOV, N. e PANGLE, T. "Leo Strauss y la Historia de la Filosofía Política". In:

Histoire de la philosophie politique. Trad. francesa de Olivier Sedeyn. Paris: PUF, 1994.

VON DER HEYDTE, F. Die Geburtsstunde des souveränen Staates. Ein Beitrag zur

Geschichte des Volkrechts, der allgemeinen Staatslehre und des politischen Denkens. Regensburg, 1952. 